$\begin{array}{ll} & \text { Etnográfica } \\ \text { etnográfica } & \text { Revista do Centro em Rede de Investigação em }\end{array}$

Antropologia

vol. $20(2) \mid 2016$

Vol. $20(2)$

\title{
Crônicas da morte revivida na luta: uma etnografia da Romaria dos Mártires da Caminhada em Ribeirão Cascalheira (MT), Brasil
}

Chronicles of death revived in the struggle: an ethnography of the Martyrs of the Walk Pilgrimage in Ribeirão Cascalheira (Mato Grosso, Brazil)

\section{Edimilson Rodrigues de Souza}

\section{(2) OpenEdition}

\section{Journals}

\section{Edição electrónica}

URL: https://journals.openedition.org/etnografica/4306

DOI: 10.4000/etnografica.4306

ISSN: 2182-2891

\section{Editora}

Centro em Rede de Investigação em Antropologia

\section{Edição impressa}

Data de publição: 1 junho 2016

Paginação: 339-362

ISSN: 0873-6561

\section{Refêrencia eletrónica}

Edimilson Rodrigues de Souza, «Crônicas da morte revivida na luta: uma etnografia da Romaria dos Mártires da Caminhada em Ribeirão Cascalheira (MT), Brasil», Etnográfica [Online], vol. 20 (2) | 2016, posto online no dia 29 junho 2016, consultado o 11 fevereiro 2022. URL: http:// journals.openedition.org/etnografica/4306 ; DOI: https://doi.org/10.4000/etnografica.4306

\section{(c) (†) \&}

Etnográfica is licensed under a Creative Commons Attribution-NonCommercial 4.0 International License. 


\section{Crônicas da morte revivida na luta: uma etnografia da Romaria dos Mártires da Caminhada em Ribeirão Cascalheira (MT), Brasil}

\section{Edimilson Rodrigues de Souza}

A proposta deste artigo é problematizar alguns aspectos que compõem rituais de sacralização de lideranças populares, assassinadas em áreas de intenso conflito fundiário no Brasil, e sua transformação em mártires da terra. A Romaria dos Mártires da Caminhada, que fundamentará esta incursão analítica, aconteceu entre os dias 16 e 17 de julho de 2011 , em Ribeirão Cascalheira (Mato Grosso, Brasil). A agência desses mártires parece estar fundamentada em habilidades individuais, reconhecidas e legitimadas no interior do próprio grupo, tanto pelas trajetórias de luta e resistência quanto pelo seu percurso de formação por religiosos e missionários católicos ligados à Teologia da Libertação. Nessa direção, se enquanto vivos sua atuação junto a grupos camponeses e indígenas era intensa, depois de mortos sua presença é frequentemente acionada e ritualizada. Esse empreendimento sugere que a lembrança ativa do morto, atrelada à lembrança ativa da luta, possibilita a presença ativa do morto na luta.

PALAVRAS-CHAVE: mártir da terra, romaria, narrativas, sacralização.

Chronicles of death revived in the struggle: an ethnography of the Martyrs of the Walk Pilgrimage in Ribeirão Cascalheira (Mato Grosso, Brazil) - The purpose of this article is to discuss some aspects that compose a ritual sacralization of popular leaders, killed in areas of intense land conflicts in Brazil, and their transformation into martyrs of the land. The Martyrs of the Walk Pilgrimage which provides the basis for this analytical incursion took place between 16 and 17 July 2011 , in Ribeirão Cascalheira (Mato Grosso). The agency of these martyrs seems to be based on individual skills, recognized and legitimized within the group itself, both because of their trajectories of struggle and resistance and their training by religious and Catholic missionaries linked to the Liberation Theology. In this direction, if while living their work with peasants and indigenous groups was intense, when they are dead their presence is often triggered and ritualized. This enterprise suggests that the dead man's active memory, linked to the active memory of the struggle, enables the active presence of the dead in the struggle.

KEYWORDS: martyrs of the land, pilgrimage, narratives, sacralization.

SOUZA, Edimilson Rodrigues de (edimilsonrondon@gmail.com) - PPGAS-Unicamp, Universidade Estadual de Campinas, Brasil. 


\section{NESTE TEXTO, TENTAREI RECUPERAR QUESTÕES PERTINENTES AO} debate que relaciona assassinatos violentos de lideranças populares e sua processual transformação em "mártires da terra”, partindo da etnografia realizada na cidade de Ribeirão Cascalheira, Mato Grosso, Brasil, em julho de 2011 , onde está localizada a Galeria dos Mártires da América Latina. ${ }^{1}$

Durante os trabalhos de campo realizados entre 2010 e 2013 (Souza 2013) emergiram questões ligadas à violência fundiária nas regiões Amazônica e do Nordeste brasileiro, que sugeriram uma ideia de vida e morte contrária à descontinuidade entre "nós", os vivos, e "eles", os mortos, relacionando lideranças camponesas, indígenas, sindicais e religiosas assassinadas nessas localidades aos movimentos de luta pela terra (Comerford 1999, 2003; Loera 2006; Borges 2011 ; Rosa 2012), transformando estes mortos em "mártires”, i.e., em modelos de ação.

A análise aqui proposta evidenciará outros pontos de vista (ou possibilidades de mundo) para pensar vida e morte, pois esta fronteira, aparentemente intransponível, uma vez atravessada (e marcada) pela violência física e simbólica que inscreve o sacrifício, revela um possível trânsito entre líder e grupo, corpo e alma, numa relação de domínio que transcende o indivíduo, notadamente a partir do seu assassinato (Mauss 2005; Mauss e Hubert 2003; Losonczy 1998, 2003; Borges 2011 ; Pérez 2012; Rosa 2012).

Este tema será devidamente explorado nas seções seguintes, mas já posso antecipar que o tema da morte revela-se em níveis de domínio distintos, o que sugere que os mortos martirizados transformam-se num dispositivo de força na luta pela terra e apresentam uma forma mítica, quase divina, mas ainda humana, uma vez que são incorporados às lutas cotidianas.

\section{ROMARIAS E LUTA PELA TERRA}

A partir das narrativas dos interlocutores desta pesquisa e das análises produzidas em outros contextos etnográficos (Losonczy 1998, 2003; Aubin-Boltanski 2007; Borges 2011 ; Pérez 2012; Rosa 2012), é possível sugerir que não há em algumas cosmologias uma distinção rígida entre vida e morte; em vez disto, evidencia-se permeabilidade e conectividade mútuas entre estes dois mundos, sobretudo em contextos sociais marcados por fluxos de relações contínuas e atualizados pelas condições de vida de muitos povos.

1 Este artigo é uma versão atualizada do segundo capítulo da dissertação de mestrado $A$ Morte sob Outro Ponto de Vista: Transformação do Líder Morto em Mártir-Encantado (Souza 2013). Quero registrar aqui os meus agradecimentos pelos comentários e contribuições da orientadora, Celeste Ciccarone, e dos membros da banca examinadora: Emília Pietrafesa de Godoi, Paulo César Scarim, Sandro José da Silva e Sônia Missagia de Mattos. 
Estes elementos revelam uma teoria do morto, expressa nos rituais e peregrinações, e ativada pela morte na luta. Com este foco, poderei explorar outros pontos de vista sobre a morte, traduzida em violência (Losonczy 1998, 2003; Pérez 2012). Esta análise tencionará, assim, compor uma topologia da escatologia que fabrica, na medida em que transforma o líder morto em mártir da terra.

Desse modo, tentarei relacionar três questões que serão evidenciadas na etnografia: a lembrança ativa do morto, atrelada à lembrança ativa da luta, parece provocar a presença ativa do morto na luta.

Para entender sumariamente o contexto histórico do qual emergem estas questões, vale explicar que a Amazônia brasileira tem vivenciado processos de colonização potencializados na segunda metade do século XX com a abertura das rodovias Belém-Brasília, Cuiabá-Santarém, Perimetral Norte e Transamazônica, o que provocou intensos fluxos migratórios para a região. Estas rodovias compunham o Plano de Integração Nacional (PIN) e mobilizaram grupos de camponeses, especialmente entre as décadas de 1960 e 1970. Contudo, ao estruturar essa política de "integração", os órgãos governamentais desconsideraram a ocorrência de diversos fluxos migratórios anteriores, de populações camponesas, assim como a existência de povos indígenas de variadas etnias (Velho 1976, 1982; DaMatta e Laraia 1978; Ianni 1978; Martins 1980, 1984, 2009; Guerra 2001; Hébette 2004; Pereira 2004, 2013; Lombardi 2013).

Esses acontecimentos produziram inúmeras formas de violência, invasões, e também negociações e barganhas entre índios e não índios ou mesmo entre diferentes povos indígenas (DaMatta e Laraia 1978; Ianni 1978; Martins 2009). A eclosão desses conflitos evidencia-se especialmente a partir da ocupação de terras devolutas, ou seja, propriedades públicas sem titularidade e por isso legalmente pertencentes ao Estado, e da concessão dessas terras a grandes empresas agropecuárias pelos órgãos estatais (Hébette 2004; Pereira 2013).

O estímulo à migração que justificava a resolução de conflitos fundiários, especialmente no Nordeste e Sudeste do Brasil, resultou na geração de novos conflitos em torno dos mesmos dilemas e da posse da terra. Descentralizando o problema, não se imaginou que pudessem ser organizadas novas formas de ocupação e resistência, em outros espaços de disputa. A confluência desses atores e a diversidade dos seus interesses tensionou a eminência de confrontos carregados de violência física e simbólica, seguida por desapropriações e mortes (Hébette 2004; Pereira 2013).

O protagonismo destas lutas por terra passa a ser delineado pela atuação de lideranças populares camponesas, indígenas, sindicais e agentes religiosos, frequentemente assassinadas e qualificadas posteriormente como mártires da terra por setores progressistas da Igreja Católica: Comissão Pastoral da Terra (СPT) e Conselho Indigenista Missionário (CIMI). 
Se enquanto vivos sua atuação junto a grupos camponeses e indígenas era intensa, depois de mortos sua presença é frequentemente acionada em reuniões políticas e religiosas, seja em eventos ordinários como encontros nos Sindicatos dos Trabalhadores Rurais (STR), nas explicações das leituras bíblicas durante missas ou reuniões religiosas e conversas informais entre amigos, seja em eventos extraordinários como romarias anuais ou manifestações públicas. Em todos esses casos pude perceber que a agência desses mártires parece estar fundamentada em habilidades individuais, reconhecidas e legitimadas no interior do próprio grupo, tanto pelas trajetórias de luta e resistência quanto pelo seu percurso de formação por religiosos e missionários católicos ligados à Teologia da Libertação.

A realização de romarias e peregrinações com o objetivo de homenagear, rememorar e ritualizar estes líderes mortos e martirizados parece funcionar como um operador da luta pela terra e pela vida nestas regiões do Brasil (Comerford 1999, 2003; Loera 2006). Estudos anteriores sobre romarias e peregrinações já demonstraram o caráter polissêmico deste tipo de ritual. Os trabalhos organizados por Simon Coleman e John Eade (2004), por exemplo, atentam para a ideia de movimento nestes rituais, ainda que não haja deslocamento espacial, e reforçam o caráter afetivo e simbólico das peregrinações, como ato vivido pelo peregrino. Para estes autores a peregrinação não pode ser explicada apenas pelo seu caráter de liminaridade ou communitas ${ }^{2}$ como sugeriu Turner (2008; Turner e Turner 2011 1), pois nela estão presentes diversos atores que transitam do universo sagrado ao profano.

Assim, os símbolos rituais deixam de ser vistos como forma transitória entre uma estrutura e outra e passam a ser analisados como contínuos e multissituados. As romarias, nestes termos, podem ser tomadas como atos tanto religiosos quanto políticos ou como culturas em movimento (Eade e Sallnow 1991; Steil 1996; Hervieu-Léger 1999; Coleman e Eade 2004; Menezes 2004; Aubin-Boltanski 2007; Braga 2008; Carminati 2014).

Sobre a articulação entre romarias e luta pela terra no Brasil destaca-se o trabalho de Osnera Pinto da Silva, que problematiza a relação entre mortes violentas, romarias e conflitos pela posse da terra no estado do Pará. No texto intitulado Caminhando pelos Mortos, Caminhando pela Vida: Conflitos, Romarias e Santidade no Sudeste Paraense (c. 1980 - c. 2010), a autora analisa duas peregrinações: a Romaria da Libertação - motivada pela morte de duas crianças, Elizabete e Elineuza, em 17 de setembro de 1980 -, e a Caminhada Irmã Adelaide - que rememora a trajetória da religiosa Adelaide Molinari, assassinada em 14 de abril de 1985 (Silva 2012: 17-18).

2 As antiestruturas ou communitas são definidas como lugar liminar onde se estabelecem relações entre indivíduos concretos, de forma direta e imediata, enquanto a estrutura organiza-se no plano da obrigação institucionalizada (Turner 2008, 2013; Turner e Turner 2011). 
Quanto à Romaria da Libertação, Silva (2012: 42-44) argumenta que esta peregrinação relaciona-se ao crime que ficou conhecido como "a chacina de Tucuruí" ou "o caso Aragão", no então povoado de Goianésia do Pará (PA), no qual foram assassinados Vicente de Pádua Justo e suas duas filhas: Elizabete (quatro anos) e Elineuza (um ano e quatro meses). As duas crianças foram mortas e queimadas diante da mãe. As razões do crime não foram explicadas, nem foi possível conectá-lo aos conflitos agrários da época. No entanto, ele foi o ponto de partida para a romaria que é organizada há mais de 30 anos no local. Silva explica que, se por um lado a chacina não pode ser relacionada aos conflitos fundiários latentes no sudeste do Pará, por outro "a romaria foi uma das formas encontradas pelo povo de combater a violação dos seus direitos e a matança dos posseiros" (2012: 45-47).

Quanto à Caminhada Irmã Adelaide, sua origem está explicitamente relacionada aos conflitos fundiários e disputas entre fazendeiros e posseiros na mesorregião sudeste paraense, especificamente nos municípios de Curionópolis e Eldorado dos Carajás, onde a religiosa residia e exercia seu trabalho missionário. A religiosa sofreu um atentado na década de 1980, enquanto conversava com o delegado sindical Arnaldo Delcídio Ferreira, do Sindicato dos Trabalhadores Rurais de Eldorado dos Carajás (Silva 2012: 49-50).

De acordo com a análise de Silva (2012: 47-49, 55-56), os assassinatos, tanto das duas crianças quanto da religiosa, aqui descritos sinteticamente, resultaram em romarias que intencionam rememorar os acontecimentos violentos e retomam, nos seus repertórios, os conflitos em torno da terra, assim como a atenção aos direitos humanos, que têm sofrido severas violações nessas áreas.

Distinções importantes podem ser apontadas entre essas duas romarias e a peregrinação por mim acompanhada em Ribeirão Cascalheira. Para a autora, as caminhadas empreendidas nos dois rituais estão centradas na devoção aos santos populares, não reconhecidos oficialmente pela Igreja Católica, e os devotos podem ser classificados em dois grandes grupos: os que buscam milagres e os que cumprem promessas. Nos dois casos, os peregrinos percorrem dezenas de quilômetros até os locais nos quais foram assassinadas a Irmã Adelaide e as crianças Elizabete e Elineuza, com chegada programada para o dia e mês dos acontecimentos que elegeram-nas à condição de mártires (Silva 2012: 58-61).

Nessas duas romarias, o tônus dos rituais está mais próximo da busca por milagres ou devoção a santos populares, uma vez que é dada atenção especial às promessas com várias finalidades: recuperação da saúde, resolução de problemas financeiros, aquisição da casa própria (2012: 106-107). Já no caso dos romeiros de Ribeirão Cascalheira o tônus é mais reativo, no sentido de que os mártires estão diretamente relacionados com a luta pela terra e pela vida (Comerford 1999, 2003; Loera 2006). Portanto, enquanto nos dois primeiros casos há uma relação entre o martírio, milagres e luta pela terra, no terceiro 
caso há uma relação específica apenas entre martírio e luta, uma vez que a força do mártir, nos termos dos peregrinos de Ribeirão Cascalheira, é rememorada e retomada no interior dos enfrentamentos pela posse da terra e pelo direito à vida. Na etnografia realizada no Estado do Mato Grosso os mártires são evidenciados como modelos de ação, não lhes são atribuídos milagres, nem tampouco são alvos de promessas.

Os elementos descritos por Christine de Alencar Chaves, em seu livro A Marcha Nacional dos Sem-Terra: Um Estudo sobre a Fabricação do Social (2000), por sua vez, podem elucidar melhor essa conexão entre procissões e ação política, sem apelar para uma conotação relacionada a milagres alcançados individualmente. Neste sentido tentarei mostrar aproximações entre esta marcha e a romaria organizada em Ribeirão Cascalheira em 2011.

A Marcha Nacional dos Sem-Terra aconteceu entre os dias 17 de fevereiro e 17 de abril de 1997, e foi assim descrita:

“[...] a caminhada dos sem-terra foi constituída por três 'colunas', que buscaram atravessar pontos diversos do território brasileiro, seguindo itinerários diferentes rumo a Brasília. São Paulo, Governador Valadares e Cuiabá [Brasil] foram as cidades escolhidas como ponto de partida das três Colunas, compostas por integrantes do MST [Movimento dos Trabalhadores Rurais Sem Terra] - "acampados" e "assentados" - de diferentes estados da federação, no empenho em dar à marcha uma representação nacional. Com atos públicos nas cidades de origem, ela teve início em 17 de fevereiro.

[...] O 17 de abril foi escolhido para término do percurso com a chegada a seu destino, a capital do país [Brasília], por ser a data do massacre de Eldorado dos Carajás, no Pará, ocorrido um ano antes - convertida em dia internacional de luta pela reforma agrária" (Chaves 2000: 13-14).

Algumas questões que já aparecem nesta primeira descrição da marcha nacional podem ser conectadas à Romaria dos Mártires da Caminhada. A primeira delas é a representação nacional, estimulando a participação de diversos estados do Brasil. A segunda é a relação entre a peregrinação e um acontecimento violento envolvendo membros dos grupos de caminhantes: o massacre de Eldorado de Carajás torna-se o epicentro da Marcha do Movimento dos Trabalhadores Rurais Sem Terra (MST).

Nestes termos, a romaria e a Marcha Nacional dos Sem-Terra analisada por Christine de Alencar Chaves assemelham-se em eficácia, na medida em que podem ser consideradas "em termos de ação coletiva expressiva, cuja importância teve por suposto a capacidade de comunicar os fundamentos ideológicos e o propósito político" desses movimentos. E, nesta circulação, evocam "referências simbólicas consagradas" (Chaves 2000: 15). 
"Feita de palavras de ordem bradadas em uníssono, gestos sincronizados por um mesmo ritmo, movimentos cadenciados em uma só direção, a mística é palavra e ato, pensamento e emoção. A mística constitui, portanto, uma unidade construída por regras que criam uma uniformidade, através da cadência sincronizada de palavras e atos que, produzidos conjuntamente, modulam um só sentido. [Seus símbolos, atos e palavras] conformam-lhe sentido, são como setas que endereçam a potência coletiva a um alvo definido pela 'luta'” (Chaves 2000: 85).

A mística da marcha do MST, análoga à dos romeiros dos mártires da caminhada, constrói unidade na diversidade e aproxima dilemas e demandas aparentemente dispersas e distantes geograficamente. $\mathrm{O}$ ato (a romaria e a marcha) e a narrativa inscrita na peregrinação rememoram enfrentamentos, dificuldades, violência e mortes. Tanto na minha experiência etnográfica quanto no caso analisado por Christine Chaves (2000), estes elementos parecem funcionar como agenciadores de um modelo de luta que constrói um projeto coletivo de vida. Nele aparecem demandas por direitos coletivos: terra, saúde, educação, condições dignas de sobrevivência, entre outros.

\section{A ROMARIA DOS MÁRTIRES DA CAMINHADA}

A 5. ${ }^{a}$ Romaria dos Mártires da Caminhada aconteceu entre os dias 16 e 17 de julho de 2011, em Ribeirão Cascalheira (MT). Esta romaria constitui um marco histórico importante na trajetória da luta pela terra de camponeses e indígenas da região. A primeira romaria foi realizada em 1986, dez anos após o assassinato do padre João Bosco Penido Burnier, a segunda em 1996, e a partir de então começou a ser organizada a cada cinco anos, em 2001, 2006 e 2011 , estando a próxima prevista para 2016 . Ela reúne povos indígenas, camponeses, organizações não governamentais (ONG), Sindicatos de Trabalhadores Rurais (STR) e setores progressistas da Igreja Católica, particularmente a Comissão Pastoral da Terra (CPT) e o Conselho Indigenista Missionário (CIMI).

Nesta localidade foi assassinado, em 11 de outubro de 1976, o padre João Bosco Penido Burnier. Sua morte revela-se como um marco na fabricação da ideia de martírio pelas Comunidades Eclesiais de Base (CEB) e pela Teologia da Libertação. Em decorrência deste assassinato, Ribeirão Cascalheira tornou-se referência na celebração dos mártires da terra e sede da Galeria dos Mártires da América Latina (figura 1). Nesta galeria são abrigadas imagens de lideranças assassinadas em decorrência de conflitos fundiários.

Nesta imagem, a Galeria aparece à direita. Atualmente, a celebração martirial do Padre João Bosco é realizada na parte externa do Santuário, pois o número de peregrinos cresceu nos últimos anos. Ganha destaque na cena uma das bandeiras com imagens dos mártires, confeccionada artesanalmente e 


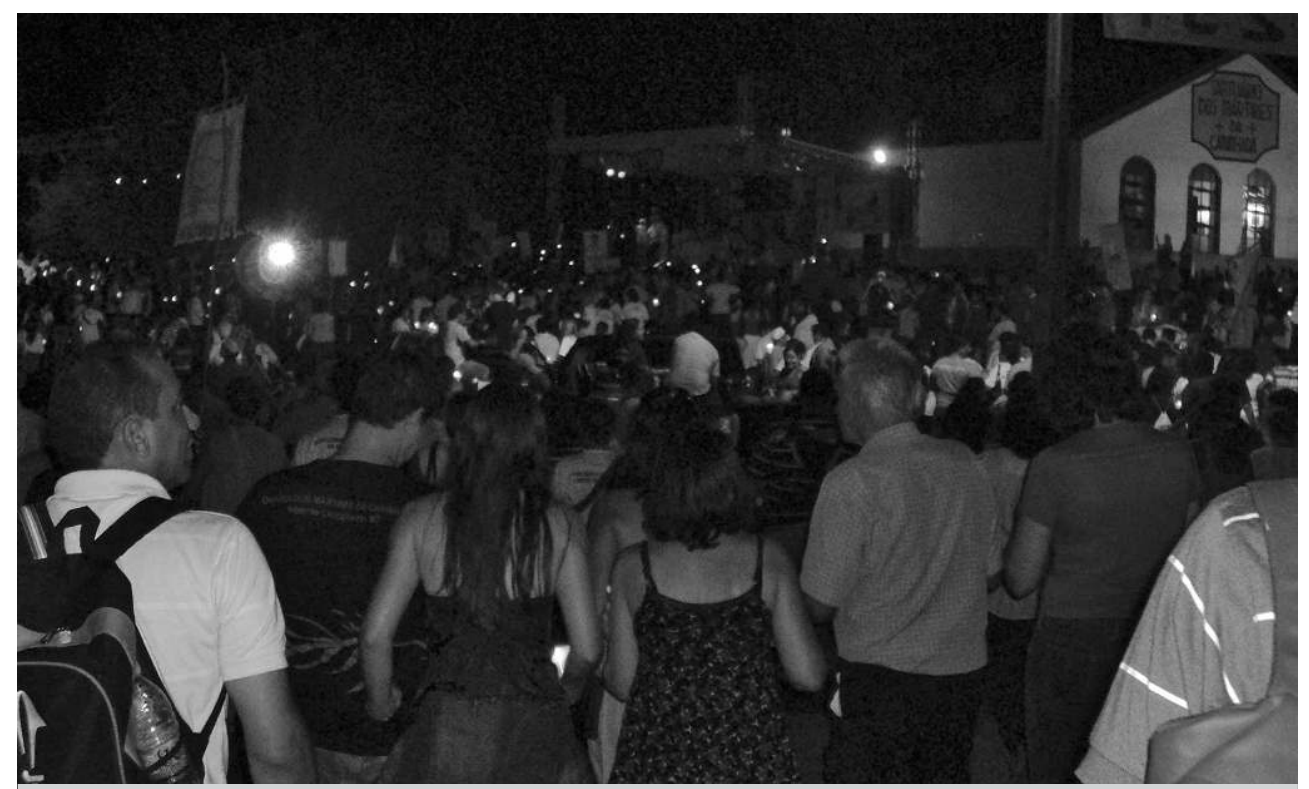

Figura 1 - Chegada dos romeiros à Galeria dos Mártires, Ribeirão Cascalheira (MT). Foto: Edimilson Rodrigues de Souza, 2011.

carregada pelos romeiros pelos mais de cinco quilômetros percorridos na noite do dia 16 de julho de 2011.

A peregrinação, que comemorou em 2011 vinte e cinco anos de história, reuniu aproximadamente 1600 romeiros, ${ }^{3}$ vindos de todas as regióes do Brasil, e de outros países, como Alemanha, Espanha e Itália. Entre eles, estavam presentes alguns representantes dos povos indígenas Guarani Kaiowa, Xukuru do Ororubá e Xavante.

Cada romaria é preparada ao longo de cinco anos, logo que se encerra a anterior, sendo de responsabilidade das comunidades da Prelazia de São Félix do Araguaia ${ }^{4}$ a preparação e confecção de painéis, provisão de alimentos, organização da hospedagem dos romeiros, sempre de forma conjunta.

A principal intenção desses romeiros ao se encontrar em Ribeirão Cascalheira a cada cinco anos é rememorar lideranças assassinadas violentamente em zonas de intenso conflito fundiário. Nesta ação, esses grupos e movimentos fabricam o sacrifício (Mauss e Hubert 2003) desses líderes através dos atos de ritualização e sacralização, que os elegem a mártires da terra.

3 Fonte: organizadores da Romaria dos Mártires da Caminhada, 2011.

4 A Prelazia de São Félix do Araguaia é composta pelos municípios Alto Boa Vista, Serra Nova Dourada, Canabrava do Norte, Porto Alegre do Norte, Confresa, São José do Xingu, Vila Rica, Santa Terezinha, Ribeirão Cascalheira e Querência, todos no estado do Mato Grosso, Brasil. 
Neste ritual o termo mártir assume também configuração política, sobretudo a partir do agravamento de situações de conflito no campo, que culminou com a criação, em 1975, da Comissão Pastoral da Terra (CPT), ligada à Conferência Nacional dos Bispos do Brasil (CNBB). Os agentes da CPT procuram articular e organizar politicamente os trabalhadores rurais e fazer intermediação na resolução de conflitos de terra. Ao reivindicar as desapropriações de terras com base no Estatuto da Terra (Lei n. ${ }^{\circ} 4.504$, de 30/1 1/1964) essa instituição defende uma concepção sobre a relação entre fé e vida, atribuindo aos líderes dos movimentos sociais mortos nesses conflitos uma caracterização sagrada de doação da vida pelas causas sociais da humanidade (Pereira 2004; Murphy 2008).

É importante frisar que os enfrentamentos relacionados aos conflitos fundiários nessas áreas ganharam força e visibilidade política com a emergência de ideais progressistas no interior da Igreja Católica, a Teologia da Libertação.

Matias Martinho Lens, ao analisar a Teologia da Libertação, explica que este movimento se caracteriza por uma prática cristã libertadora, "não só escatológica, mas buscada na história; [...] uma libertação simultaneamente na instância econômica, política e religiosa, entendidas como totalidade" (1992: 125). Para o autor, esta concepção teológica formulada após o Concílio Vaticano II (na primeira metade da década de 1960) "tenta traduzir para o campo religioso as críticas aos sistemas levantadas pela análise social" (1992: 125). Dela emergem organizações pastorais militantes que trabalham junto a grupos marginalizados socialmente, das quais Lens cita: Comunidades Eclesiais de Base (CEB), Comissão Pastoral da Terra (CPT), Pastoral Operária (PO) e Conselho Indigenista Missionário (CIMI). Todos eles caracterizam-se pela conotação social e política das práticas religiosas (Lens 1992: 125).

Entre suas principais ações destaca-se: "uma importante releitura de conceitos, concepções teológicas e textos religiosos, inclusive a Bíblia, lida agora por Comunidades Eclesiais de Base à luz de sua prática libertadora e como inspiradora da opção preferencial e 'evangélica' pelos pobres" (Lens 1992: 125).

Na Prelazia de São Félix do Araguaia essas organizações pastorais articuladas aos Sindicatos dos Trabalhadores Rurais promovem uma série de movimentos populares, atos de resistência camponesa e indígena, e elaboram estratégias de ação com base na figura de seus líderes mortos.

Nesses atos de resistência, a evocação da figura do líder martirizado permite construir um lugar privilegiado de elaboração social de um personagem. Os líderes mortos e processualmente martirizados ganham visibilidade social e política através de narrativas que relacionam modelos de ação à eficácia simbólica das práticas ritualísticas (Peirano 2002, 2003), nas quais analogias e aproximações, traduções e transposições propiciam a produção da crença na presença desses mártires. Este tema será explorado no tópico seguinte. 


\section{ATORES, CENÁRIOS E SÍMBOLOS DA ROMARIA}

João Bosco Penido Burnier (figura 2) era padre, missionário jesuíta e coordenador da Regional do CIMI no nordeste do Mato Grosso, Brasil, e sua trajetória biográfica, narrada por Pedro Casaldáliga, ${ }^{5}$ inicia-se no encontro entre ele e os diversos grupos indígenas que viviam nas áreas da foz do rio Araguaia:

"Era tarde do dia 11 de outubro de 1976. Duas mulheres sertanejas, Margarida e Santana, estavam sendo torturadas na cadeia-delegacia de Ribeirão Bonito, lugar e hora de latifúndio prepotente, de peonagem semiescrava e de brutalidade policial. A comunidade celebrava a novena da padroeira, Nossa Senhora Aparecida. E nesse dia eu havia chegado ao povoado com o padre João Bosco. Nós dois fomos interceder pelas mulheres torturadas. Os policiais nos esperavam no terreiro da delegacia e apenas foi possível um diálogo de minutos. Um soldado desfechou no rosto do padre João Bosco um soco, uma coronhada e o tiro fatal. Em sua agonia, padre João Bosco ofereceu a vida pela CIMI e pelo Brasil, invocou ardentemente o nome de Jesus e recebeu a unção. Foi morrer, gloriosamente mártir, no dia seguinte, festa da Mãe Aparecida, em Goiânia, coroando assim uma vida santa" [Entrevista concedida em 15 de julho de 2011].

João Bosco, que participava do Encontro Indigenista anual da Prelazia de São Félix do Araguaia, em outubro de 1976, esteve, nos dias que antecederam seu assassinato, junto a Pedro Casaldáliga. Ao final deste encontro, ele seguiu com o bispo para Ribeirão Bonito, ${ }^{6}$ onde aconteciam os festejos da padroeira do local, Nossa Senhora Aparecida.

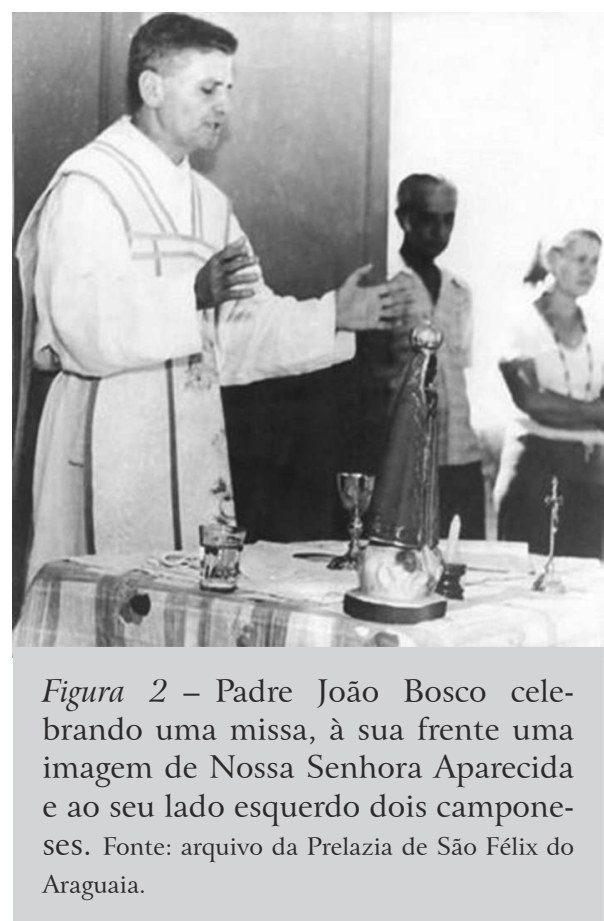

5 Bispo emérito da Prelazia de São Félix do Araguaia (MT), Pedro Casaldáliga, inspirado pela Teologia da Libertação, exerce desde a década de 1970 um importante papel como mediador dos conflitos decorrentes da implementação de grandes projetos latifundiários na região norte do Mato Grosso. 6 O município de Ribeirão Cascalheira resulta da junção de dois povoados, Ribeirão Bonito e Alta Cascalheira; o nome Ribeirão foi atribuído pelos primeiros colonos que se fixaram à beira do córrego (pequeno riacho) Suiazinho, quilômetros adiante, e o outro povoado foi denominado Cascalheira devido à presença de cascalho (pedra britada ou lascas de pedra). 
Ali, o padre pernoitaria e depois seguiria para a aldeia dos bakairi, onde desenvolvia seus trabalhos missionários. $\mathrm{O}$ vilarejo, no entanto, estava tomado por um clima de tensão, decorrente da morte de um cabo da polícia, em 1971, que trouxe ao lugar um destacamento de policiais que, nas palavras de Casaldáliga, reprimiam e torturavam posseiros da área. ${ }^{7}$

Chegando ao povoado, os dois religiosos tomaram conhecimento de que duas mulheres, Margarida e Santana, estavam sofrendo torturas na delegacia. Casaldáliga resolve ir ao local interceder por elas, e João Bosco decide acompanhá-lo.

Ao chegar à delegacia eles encontram alguns policiais e num breve diálogo João Bosco sofre um atentado, por parte de um dos cabos, que deflagra sobre o padre uma bofetada e na sequência uma coronhada de revólver e um tiro no crânio.

Sobre este encontro entre João Bosco e os polícias ouvi várias versões. Numa delas os policiais haviam confundido o missionário com o bispo Casaldáliga, pois o bispo vestia-se com muita simplicidade, enquanto o padre usava roupas de religioso e portava clergyman. ${ }^{8}$ Outros peregrinos contaram-me que, quando os policiais perguntaram quem dos dois era o bispo, João Bosco se apresentou como tal, pois suspeitou que eles fossem atirar em Casaldáliga. Numa terceira versão do assassinato, os peregrinos explicaram que ao averiguar a condição de tortura das duas mulheres, o padre ameaçou denunciar os policiais aos seus superiores.

Em todos os relatos, o padre "ofereceu sua vida pelas vidas": do bispo, das mulheres presas e torturadas e dos índios e camponeses da área. Esta oferta voluntária o transformou em mártir.

A Galeria dos Mártires, conhecida também como Santuário dos Mártires da Caminhada, foi construída no mesmo local onde o padre João Bosco foi baleado pelo policial. Em entrevista, Casaldáliga atribuiu a construção da Galeria a um protesto dos moradores de Ribeirão Cascalheira, que, no 7. ${ }^{\circ}$ dia da morte do referido padre, destruíram a delegacia e posteriormente construíram o santuário.

A figura 3 é da delegacia destruída pelos moradores de Ribeirão Bonito. Note-se à esquerda da imagem a Cruz da Libertação, fincada no dia da derrubada, na qual se lê a inscrição: "aqui no dia 11/10/76 foi assassinado por soldado PM [Polícia Militar] o Pe. João defendendo a liberdade”.

A Romaria dos Mártires da Caminhada atualiza o percurso feito por João Bosco e Casaldáliga, bem como o caminho dos posseiros que retornaram à

7 Entre 1964 e 1985 o Brasil foi tomado por forças repressivas do regime civil-militar, que atingiram inclusive populações camponesas, vítimas de prisões e tortura, entre outras formas de violência (Pereira 2013).

8 Filete branco utilizado por alguns padres, que se encaixa sob o colarinho da camisa. 


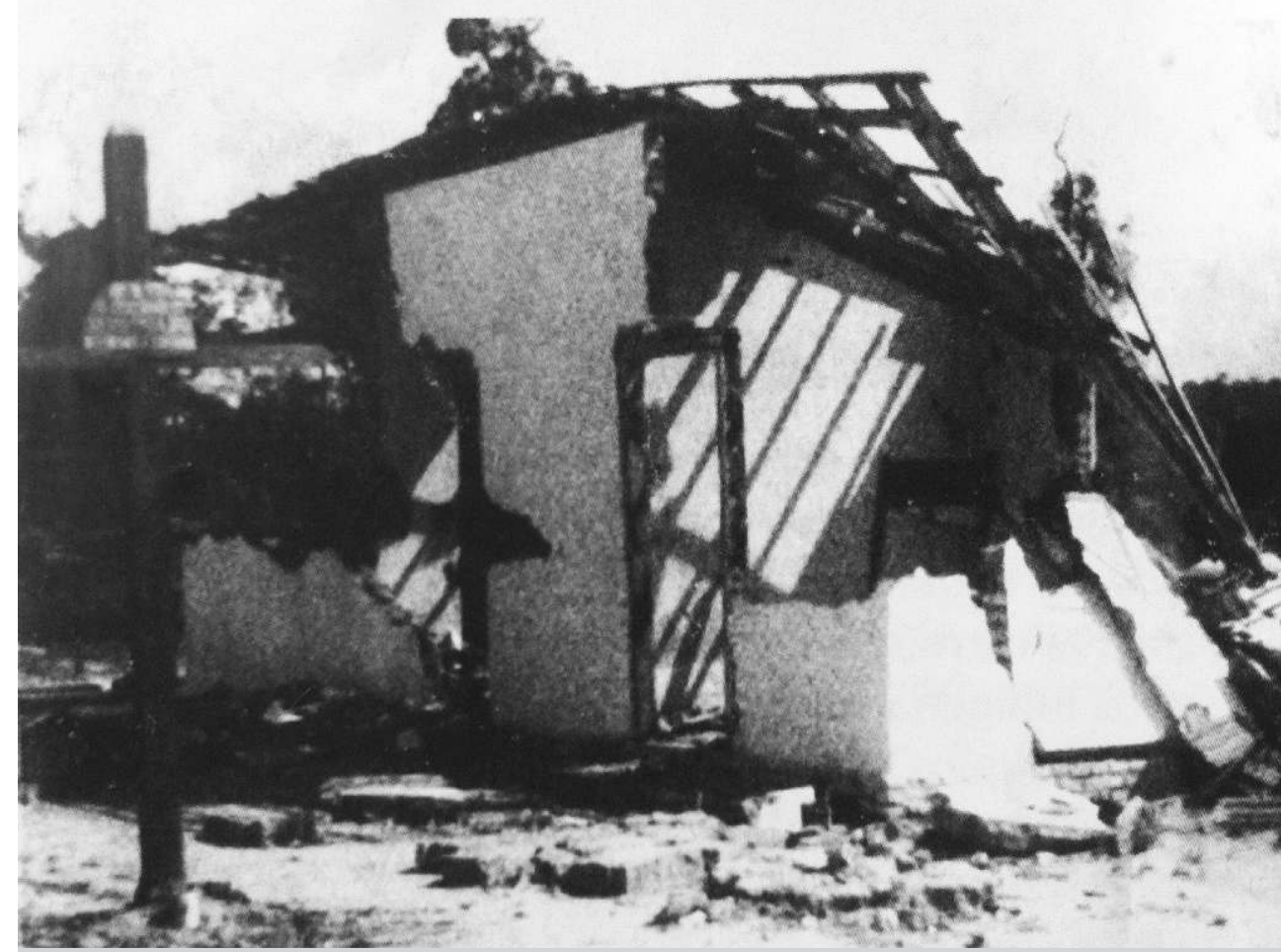

Figura 3 - Cadeia-delegacia derrubada no 7. ${ }^{\circ}$ dia do assassinato de João Bosco. Ribeirão Cascalheira (MT), 1976. Fonte: Galeria dos Mártires.

delegacia para destruí-la e construir posteriormente, no local, a Galeria dos Mártires.

Nos três dias que antecedem o ritual principal são realizadas celebrações que desencadeiam o processo de elaboração da sacralização dos mártires através da partilha de suas histórias. Numa dessas noites, registrei a acolhida dos romeiros na capela que teria sido o lugar onde o padre João Bosco recebeu os primeiros socorros, antes de ser levado para a cidade de Goiânia, estado de Goiás, Brasil, local do seu falecimento. Os momentos que precedem este rito são marcados por cantos, danças e imagens que contribuem na montagem expressiva das narrativas sobre o martírio.

"Neste lugar, terra sagrada, aconteceu a agonia do padre João Bosco [...]. Foi uma morte muito simbólica. Eu vou recordar que o padre João Bosco era um jesuíta, de uma família distinta e teve cargos na companhia de Jesus de prestígio, e que ele havia feito a opção pelos pobres, pelas margens. Ele havia na verdade deixado os colégios de luxo, deixado as comunidades do Rio, de São Paulo, e vindo para o interior. Símbolo dos santos dos pobres, ele foi trabalhar, 
viver e trabalhar no meio dos povos indígenas, concretamente os Pacaembu, o santo da causa indígena; e no meio dos sertanejos, posseiros dessa região do norte do Mato Grosso, o santo da reforma agrária, pelo povo sem terra. E é reconhecido também como o padroeiro das lutas contra a tortura, porque ele morreu, em última instância, porque nós dois fomos tentar libertar duas mulheres que estavam sendo torturadas. Ele morreu por defender da tortura essa duas mulheres, martírio simbólico de muitos outros mártires. [...] O padre João Bosco, neste sentido também, foi militante: lutou pela causa indígena, pela defesa dos pobres e foi místico. Juntou o que na maioria das vezes fica separado das nossas vidas: a militância e a contemplação" [Pedro Casaldáliga, 15 de julho de 2011 - grifos meus].

Além da delegacia que deu lugar à Galeria dos Mártires, a casa paroquial, na qual João Bosco havia recebido os primeiros cuidados após o atentado, também foi transformada em espaço sagrado. É evidente que a produção da estética do martírio predomina sobre a ocorrência da morte de João Bosco, pois mesmo tendo falecido a caminho de Goiânia (GO), onde receberia cuidados médicos, a delegacia e a casa paroquial são rememoradas como espaços da morte e sacrifício, cenários onde pode ser enfatizada a violência do assassinato.

$\mathrm{Na}$ casa paroquial transformada em capela, os grupos de romeiros começam a vivenciar os fatos que motivaram a realização da romaria: a morte do referido padre e o reconhecimento de outros mártires, espalhados pela América Latina.

$\mathrm{O}$ atentado que ocasionou a morte do padre João Bosco foi o eixo propulsor da Romaria dos Mártires da Caminhada; nele é evidenciada a mobilização coletiva e pública, materializada na destruição da cadeia e posterior construção da galeria que abriga e sacraliza as imagens-memória dos mártires (Nora 1984, 1993; Godoi 1999).

Para dar início à peregrinação uma fogueira é acesa por lideranças indígenas, enquanto Zenilda Maria de Araújo, liderança do povo Xukuru do Ororubá, ora, cantando: "Meus irmão de luz vem nos socorrer, é a sua força que vai nos valer. Força, força, meus irmão de luz. Força, força, com as ordens de Jesus", num apelo comum para receber do mártir a força para continuar lutando.

Do centro de Ribeirão Cascalheira, os caminhantes seguem rumo à galeria, ao longo de cerca de cinco quilômetros a pé. Durante o percurso, as falas, acompanhadas por música e imagens dos líderes assassinados reforçam a postura política, religiosa e ideológica desses atores, questionando a marginalização, desigualdade e má distribuição de recursos econômicos, sociais e naturais. As músicas soam como hinos populares:

\footnotetext{
"Quem disse que não somos nada

e que não temos nada para oferecer.
} 
Repare as nossas mãos abertas trazendo as ofertas do nosso viver.

A fé do homem nordestino que busca um destino e um pedaço de chão.

A luta do povo oprimido que abre caminho e transforma a nação.

Retalhos de nossa história bonitas vitórias que meu povo tem.

Palmares, Canudos, Cabanas

são lutas de hoje e de ontem também.

Aqui trazemos a semente

sangue desta gente que fecunda o chão.

Do gringo e tantos lavradores

Santos e operários em libertação.

Coragem de quem dá a vida

Seja oferecida com este vinho e pão.

É força que destrói a morte

E muda nossa sorte é ressurreição.

Ô, ô, ô, ô recebe Senhor"

("Quem disse que não somos nada", letra de Zé Vicente - grifo meu).

Neste ponto, a análise proposta por Anne-Marie Losonczy (1998, 2003) e Andrea Lissett Pérez (2012) me parece incontornável para problematizar a relação entre culto aos mortos, luta pela terra e violência.

A primeira autora percebe que há uma tênue relação entre mortes violentas e sacralização na Colômbia, ao observar as frequentes homenagens realizadas nos túmulos dos cemitérios das cidades de Bogotá e Medellín, por indivíduos ou grupos, às vítimas assassinadas (mortos recentes, anônimos ou célebres) por organizações paramilitares ou narcotraficantes, e sugere que essas ações rituais mortuárias ecoam nas dinâmicas coletivas de ritualização da violência, terror e luto (Losonczy 1998, 2003).

“[...] La présence périodique de fleurs [em túmulos anônimos no cemitério central de Bogotá], de cierges, et de remerciements écrits autour d'une tombe anonyme particulière, ainsi que le témoignage d'un homme sur les miracles d'une âme de mort y attirent des solliciteurs de plus en plus nombreux. Après quelques années, apparaît une femme affirmant être la fille de cette morte connue comme 'la Milagrosa', à laquelle elle attribue le nom de Salomé. Elle commence à vendre la photo de la défunte, puis le texte de 'as' prière. Désormais nommée, possédant une iconographie, des paroles rituelles particulières à son adresse, quelques éléments biographiques et des miracles post mortem les esquisses d'une hagiographie: d'âme anonyme de mort la voici transformée en sainte" (Losonczy 2003: 188-189). 
Para Losonczy (2003) estes rituais públicos nos túmulos ultrapassam o limite entre vida e morte e produzem uma dupla eficácia: denunciam a violência sofrida e santificam os mortos, transformando-os em figuras de proteção.

Este movimento é bem semelhante ao encontrado em Ribeirão Cascalheira, Brasil. No caminho até à delegacia transformada em santuário-galeria dos mártires (figuras 4 e 5), os peregrinos rememoram os locais de conflito e as pessoas envolvidas.
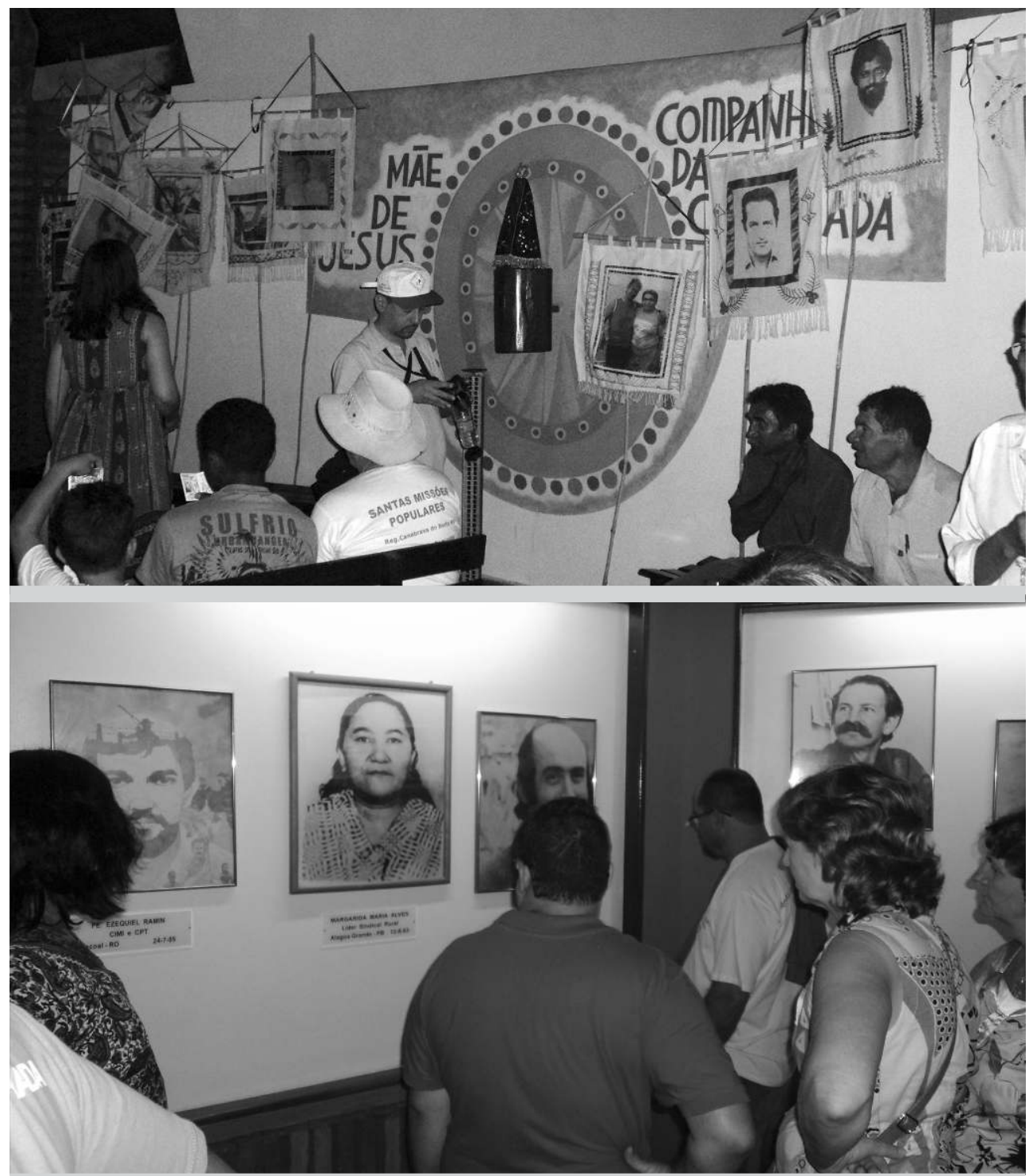

Figuras 4 e 5 - Concentração de romeiros na Galeria dos Mártires da América Latina. Foto: Edimilson Rodrigues de Souza, 2011. 
Similar ao culto aos mortos nos cemitérios da Colômbia, a Romaria dos Mártires da Caminhada também formula denúncias à violência em áreas de conflito eminente e atualiza os sentidos da luta pela terra e pelo direito à vida ao rememorar as experiências violentas que originam a condição de martírio de lideranças camponesas e indígenas. Este aspecto fica evidente nos objetivos anunciados pelos animadores, romeiros e organizadores em suas falas:

— reunir pessoas que acreditam na opção da Igreja pelos pobres e marginalizados;

- reavivar (revigorar) as forças na luta;

- rememorar os irmãos que morreram na caminhada e anunciar sua presença na luta, através das histórias de sua vida, seu engajamento político e sua morte;

- constituir e atualizar a comunidade a partir da memória do mártir [nos termos de Pedro Casaldáliga, "uma igreja que não se lembra de seus mártires não deve continuar"].

O rito possibilita, a meu ver, a produção de sentimentos que unem as pessoas em torno de um elemento comum: suas lideranças violentamente assassinadas. Os relatos sobre a morte e vida dos líderes são transformados em narrativas do martírio.

Este argumento evoca o trabalho de Andrea Lissett Pérez (2012) sobre a presença de elementos religiosos no interior de um grupo revolucionário na Colômbia, o Exército de Libertação Nacional (ELN). De acordo com a autora, este movimento é criado em 1965 por sete estudantes, ancorados na emergência de novas propostas revolucionárias, questionadoras das posturas de antigos partidos de esquerda colombianos, notadamente quanto às suas estratégias e táticas de luta política. Estas novas propostas "de luta e utopias libertárias" defendiam a luta armada como alternativa para alcançar as mudanças sociais e políticas almejadas. E para atingir este objetivo vincularam-se a diversos setores da sociedade: camponeses, intelectuais, operários, estudantes e cristãos ligados à Teologia da Libertação (Pérez 2012: 350).

Um dado importante na atuação desse movimento, que dialoga com a etnografia sobre os mártires da terra no Brasil, é a presença do sacerdote católico Camilo Torres, que na ocasião da criação do ELN havia sido afastado dos seus trabalhos pastorais por setores conservadores da Igreja Católica, mas ainda exercia forte liderança popular. A atuação de Camilo junto ao movimento, no entanto, foi abreviada pelo seu assassinato em fevereiro de 1966 por um soldado inimigo, no primeiro combate do qual participou. Este fato provocou a abertura de um espaço de participação política em diversos âmbitos cristãos, que se identificaram com o pensamento e com a vida de Camilo (Pérez 2012:351). 
De acordo com Pérez, a morte do padre Camilo marca profundamente o ELN, que o transformou em mártir da revolução colombiana e em mito reverencial dos militantes deste movimento: "Camilo interpretou e atualizou um dos mais caros preceitos do cristianismo: o sentido do sacrifício e da entrega total pelos outros. Ele encarna $[\ldots]$ o sacrifício de Jesus pela humanidade" (2012: 353).

A martirização do padre Camilo atualiza o sentido da morte para os guerrilheiros do ELN, que a transformam em algo desejado, ao atribuir aspectos de sacralidade e recriar simbolicamente o mito de salvação do cristianismo. Para a autora, três valores se articulam neste processo: "o sujeito que se sacrifica, a atitude de entrega como um ato de amor e os receptores dessa entrega, o povo" (2012: 355).

"O problema da salvação não se esgota no plano da vida, transcende com a morte e adquire um poderoso sentido simbólico: o martírio, que é a forma ideal de se perpetuar na memória dos homens. Este foi o sentido ativado com a morte do sacerdote Camilo Torres, que forneceu a metáfora perfeita para dar vida à figura do martírio dentro da organização" (2012: 359).

As figuras 6, 7 e 8 dialogam com o argumento de Pérez (2012). No conjunto iconográfico é possível reconhecer a concepção de morte difundida pelos militantes do ELN colombiano: "[...] quem morre lutando em nome da 'causa' realmente não morre, continua vivendo nos demais que permanecem na luta. Segue presente numa nova dimensão, na de 'mártir'" (2012: 361).

Por meio dessas narrativas orais e visuais, os mártires são acionados e convidados a caminhar junto aos peregrinos; ganham destaque os estandartes carregados pelos romeiros com as imagens dos mártires e algumas camisetas preparadas para o evento onde se lê "Romaria dos Mártires 2011: Testemunhas do reino". A vela é descrita pelos romeiros como símbolo da luz que guia o caminho e representa a continuidade do percurso, iluminado pela lembrança ativa do mártir.

As imagens narram o trabalho realizado pelos mártires em diversas partes do Brasil, momentos de "sua vida doada pelas vidas", podendo ser complementadas com textos afixados junto a elas, como o que afirma "o suor e sangue do mártir fecundam o chão".

"Animador: A gente pede ao pessoal que tem os estandartes [com as imagens dos mártires], com essas presenças vivas de quem deu a vida pela vida, pelo reino da vida, que possa virar-se, fazer como se fosse um círculo em volta do próprio corpo, para que todos possam visualizar em todas as direções quem são essas pessoas. E a gente pode acenar, levantado as nossas 

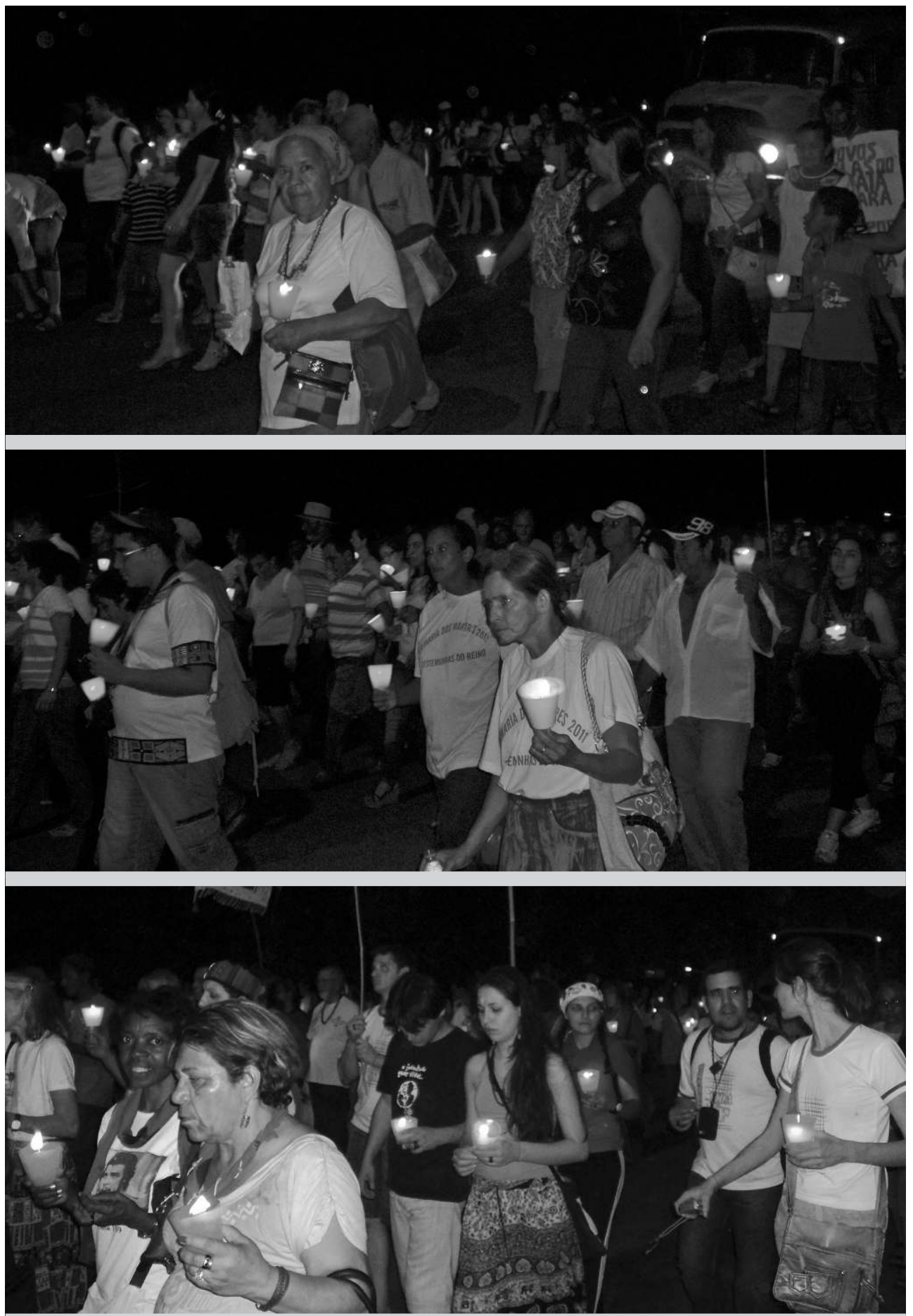

Figuras 6-8 - Peregrinos caminhando em direção à Galeria dos Mártires da América Latina. Ribeirão Cascalheira (MT). Fotos: Edimilson Rodrigues de Souza, 2011. 
velas para iluminar a presença deles e delas [referindo-se aos estandartes com a imagem dos mártires]

Animador: Antônio Conselheiro?

Coro: Presente na caminhada!

Animador: Galdino?

Coro: Presente na caminhada!

Animador: Xicão Xukuru?

Coro: Presente na caminhada!

Animador: Miriã Maria?

Coro: Presente na caminhada!

Animador: Arturo Bernal?

Coro: Presente na caminhada!

Animador: Carlos Paz?

Coro: Presente na caminhada!

Animador: Oscar Santana?

Coro: Presente na caminhada!

Animador: Juventude?

Coro: Presente nesta caminhada!

Animador: Estudantes?

Coro: Presente nesta caminhada!

Animador: Mulheres?

Coro: Presente nesta caminhada!

Animador: [referindo-se aos mártires] Continua vivo, continua presente na caminhada. São esses mártires que nos dão força e que nos ajudam a continuar na defesa da justiça. Sobre a terra o povo avança; quem espera nunca alcança!

Coro: Sobre a terra o povo avança; quem espera nunca alcança!"

[Falas registradas na Romaria dos Mártires da Caminhada, 16 de julho de 2011$]$

Nestes trechos da narrativa oral, as pessoas são convidadas pelo animador a chamar o mártir para caminhar junto a elas e a experimentar a força do líder morto na luta em defesa da justiça, especialmente. Assim, rememorar o mártir o elege a precursor da luta que avança (Losonczy 1998, 2003; Pérez 2012 ). Ele "continua vivo", repete insistentemente o animador, "presente na caminhada".

Nos relatos e nos cantos os mártires são processualmente sacralizados na medida em que são lembrados e comemorados nas falas das lideranças. A cada nome, os romeiros respondem: "presente na caminhada”. O caminhar também fabrica os romeiros e os significa (Eade e Sallnow 1991; Steil 1996; Hervieu-Léger 1999; Coleman e Eade 2004; Menezes 2004; Aubin-Boltanski 2007; Braga 2008; Carminati 2014); a peregrinação, ao mesmo tempo obrigação e 
ato voluntário, envolve um compromisso coletivo e individual: continuar a luta iniciada pelo líder sacralizado.

Os atos que conformam a Romaria dos Mártires da Caminhada reforçam a luta dos presentes, unidos ao mártir antes e depois da morte, cujo sentido se inscreve e se fixa como resistência e continuidade. A celebração do martírio é um motivo para se encontrar, partilhar o sofrimento e reunir forças para continuar resistindo (Losonczy 1998, 2003; Pérez 2012).

\section{A PRESENÇA ATIVA DO MORTO NA LUTA}

No âmbito das questões ligadas à violência fundiária nas áreas descritas ao longo deste artigo é sugestiva uma ideia de morte incomum ${ }^{9}$ que emerge nas narrativas orais e visuais sobre lideranças camponesas, indígenas, sindicais e religiosas violentamente assassinadas e processualmente martirizadas, num plano de equivalências e analogias, produzidas com a presentificação do mártir, como herói mítico (Sahlins 2008, 2011 ), num trabalho onde símbolos e metáforas operam a articulação entre sacralização e ritualização.

Os relatos sobre a trajetória de luta dos mártires parecem orientar um modelo exemplar de ação. Neste modelo, a figura do mártir é construída numa relação intersubjetiva de comoção, no envolvimento numa luta por um objetivo comum e num movimento dialógico e convergente de pertencimento, alimentando vínculos religiosos, políticos e sociais, que conjugam um sentido de sofrer com, e não sofrer só.

As experiências pessoais tornam-se, como modelo exemplar, atos coletivos e possibilitam a produção do grupo a partir dos episódios vivenciados pelos mártires, ao atualizar práticas de resistência através dessas experiências privilegiadas.

Desse modo, três questões me parecem apropriadas para pensar essas mortes violentas e a sacralização desses líderes: a lembrança ativa do morto, atrelada à lembrança ativa da luta, possibilita a presença ativa do morto na luta.

Sylvia Caiuby Novaes, num artigo intitulado "Funerais entre os bororo: imagens da refiguração do mundo" (2006), auxiliará na defesa deste argumento. Ao analisar os ritos funerários deste povo, a autora afirma que ocorre uma série de transformações no corpo e na alma do morto e nas relações sociais com os vivos.

9 Ainda sobre morte e ritos funerários é sugestiva a leitura de "A contribution to the study of the collective representation of death" (Hertz 1960); A Morte e os Mortos na Sociedade Brasileira (Martins 1983); e Os Mortos e os Outros: Uma Análise do Sistema Funerário e da Noção de Pessoa entre os Índios Krahó (Cunha 1978). 
“[...] seus cabelos [do morto] são cortados do modo tradicional, seu corpo é todo untado de urucum, seu rosto ornamentado com pinturas, e em sua cabeça são colocados adornos plumários de acordo com os padrões do clã a que ele pertence. É preciso identificar claramente esse corpo e essa pessoa que serão desfigurados após a morte.

A perda do sopro vital é o sinal da morte. A partir do momento em que se constata a perda do sopro vital, o rosto do morto é coberto por uma bandeja de palha para que, transformado em aroe (alma), não seja visto por mulheres e crianças. Essa é a primeira da longa série de transformações desencadeadas pela morte e que, como tal, deve ser mantida fora dos olhares de mulheres e crianças" (Novaes 2006: 290-291).

Neste caso, o morto é ritualmente preparado para ser processualmente esquecido e sua alma deve seguir para a aldeia dos mortos. Seus pertences são queimados e sua presença é substituída por um representante, uma alma nova. Todos os esforços são concentrados no esquecimento ativo do morto.

"Não se pronuncia o nome do morto após sua morte - este é mais um dos inúmeros traços de sua vida que deve desaparecer. As mulheres não devem saber quem é o representante do finado. [...] A desfiguração que ocorre nos funerais revela o mistério por trás da vida e da morte nessa sociedade. A morte desequilibra o cosmos, e é preciso um enorme esforço coletivo para que a vida retome seu rumo. A desfiguração é total - o corpo do morto, seu nome, seus pertences" (Novaes 2006: 302).

Se entre os bororo a morte significa a perda do sopro vital e a consequente substituição do morto pelo seu representante, aroe maiwu (alma nova), no caso dos mártires da terra ocorre o extremo oposto: a lembrança ativa do morto na luta é ritualmente elaborada.

E para mantê-los "presentes na caminhada", suas trajetórias são constantemente acessadas e por vezes magnificadas, como foi demonstrado através das narrativas dos seus grupos.

Se tomarmos os mártires da terra como expressão das lutas sociais empreendidas por camponeses e indígenas no Brasil, poderemos articulá-los num campo perceptivo imbricado de conflitos, enfrentamentos e instabilidades. Envoltos nesses dilemas e nos respectivos desdobramentos da vivência cotidiana do grupo, eles atuam na mediação, tradução e movimentação, expressos e presentificados pela potência/força evocativa das imagens dos painéis e fotografias, transitando entre "a figura e o fundo, as margens e o centro, o móvel e o ponto de referência, o transitivo e o substancial, o comprimento e a profundidade" (Deleuze e Guattari 1992: 30). 
Finalmente, é possível indicar que é atribuída aos mártires da terra, nos contextos etnográficos aqui descritos, uma invencibilidade, o que significa dizer que o morto não morre, ao contrário, retroalimenta a luta pela terra e continua "presente na caminhada".

O principal critério desta transformação, "dar a vida pelas vidas”, significa também doar sua força, sua capacidade de articulação religiosa, política e social. Este exercício poderia ser traduzido numa ação que transcende tempo e espaço, substituindo os limites físicos do corpo pelas potencialidades ilimitadas da alma. Esta, por sua vez, transita, através dos painéis, canções e narrativas visuais e orais, pelos variados espaços de enfrentamentos, fabricando formas de resistência imprevistas pelos opositores e mediando a relação entre movimentos sociais e luta pela terra. Intenciona-se, nessa investida, uma mudança no mundo social, justificando as posições tomadas frente às disparidades identificadas.

\section{BIBLIOGRAFIA}

AUbin-BOltanski, Emma, 2007, Pèlerinages et nationalisme en Palestine: Prophètes, héros et ancêtres. Paris, Editions de l'EHESS.

BORGES, Antonádia, 2011 , "Sem sombra para descansar: etnografia de funerais na África do Sul contemporânea”, Anuário Antropológico, 2010: 215-252.

BRAGA, Antônio Mendes da Costa, 2008, Padre Cícero: Sociologia de Um Padre, Antropologia de Um Santo. Bauru, SP, Edusc.

CARMinATI, Thiago Zanotti, 2014, A Dádiva da Imagem: As Promessas como Produção de Pessoas e Objetos (Etnografia em Juazeiro do Norte). Rio de Janeiro, Universidade Federal do Rio de Janeiro, tese de doutorado em Sociologia e Antropologia.

CHAVES, Christine de Alencar, 2000, A Marcha Nacional dos Sem-Terra: Um Estudo sobre a Fabricação do Social. Rio de Janeiro, Relume Dumará.

COlEMAN, Simon, e John EADE (orgs.), 2004, Reframing Pilgrimage: Cultures in Motion. Londres e Nova Iorque, Routledge.

COMERFORD, John Cunha, 1999, Fazendo a Luta: Sociabilidade, Falas e Rituais na Construção de Organizações Camponesas. Rio de Janeiro, Relume Dumará.

COMERFOrD, John Cunha, 2003, Como Uma Família: Sociabilidade, Territórios de Parentesco e Sindicalismo Rural. Rio de Janeiro, Relume Dumará.

CUNHA, Manuela Carneiro da, 1978, Os Mortos e os Outros: Uma Análise do Sistema Funerário e da Noção de Pessoa entre os Índios Krahó. São Paulo, Hucitec.

DAMATTA, Roberto, e Roque de Barros LARAIA, 1978, Índios e Castanheiros: A Empresa Extrativa e os Índios no Médio Tocantins. Rio de Janeiro, Paz e Terra.

DeleuZE, Gilles, e Félix GUATTARI, 1992, O que É Filosofia?. Rio de Janeiro, 34. 
EADE, John, e Michael J. SALLNOW (orgs.), 1991, Contesting the Sacred: The Anthropology of Christian Pilgrimage. Londres e Nova Iorque, Routledge.

GODOI, Emília Pietrafesa de, 1999, O Trabalho da Memória: Cotidiano e História no Sertão do Piauí. Campinas, SP, Unicamp.

GUERRA, Gutemberg Armando Diniz, 2001, O Posseiro da Fronteira: Campesinato e Sindicalismo no Sudeste Paraense. Belém, Edufpa/NAEA.

HÉBETTE, Jean, 2004, Cruzando a Fronteira: 30 Anos de Estudo do Campesinato na Amazônia, vols. I-IV. Belém, Edufpa.

HERTZ, Robert, 1960, "A contribution to the study of the collective representation of death", em Robert Hertz, Death and the Right Hand. Londres, Cohen and West, 27-86.

HERVIEU-LÉGER, Danièle, 1999, Le pèlerin et le converti: La religion en mouvement. Paris, Flammarion.

IANNI, Otávio, 1978, A Luta pela Terra: História Social da Terra e da Luta pela Terra Numa Área da Amazônia. Rio de Janeiro, Vozes.

LENS, Matias Martinho, 1992, "Festas religiosas, CEBs e mudanças", em Pierre Sanchis (org.), Catolicismo: Unidade Religiosa e Pluralismo Cultural. São Paulo, Loyola, 121-165.

LOERA, Nashieli Rangel, 2006, A Espiral das Ocupações de Terra. São Paulo, Polis.

LOMBARDI, Thais Tartalha do Nascimento, 2013, "Os colonos e os daqui: trajetórias e paisagens ao longo da rodovia Transamazônica”, em Emília Pietrafesa de Godoi e Marilda Menezes (orgs.), Uma Terra para Se Viver: Assentados, Colonos e Quilombolas. São Paulo, Annablume, 53-80.

LOSONCZY, Anne-Marie, 1998, "Le saint et le citoyen au bord des tombes: sanctification populaire de morts dans les cimetières urbains colombiens", Religiologiques, 18: 149-175. LOSONCZY, Anne-Marie, 2003, "Violence sociale et ritualisation de la mort et du deuil en Colombie", Autrepart, 26: 187-199.

MARTINS, José de Souza, 1980, Expropriação e Violência: A Questão Política no Campo. São Paulo, Hucitec.

MARTINS, José de Souza (org.), 1983, A Morte e os Mortos na Sociedade Brasileira. São Paulo, Hucitec.

MARTINS, José de Souza, 1984, A Militarização da Questão Agrária no Brasil. Terra e Poder: O Problema da Terra na Crise Política. Petrópolis, Vozes.

MARTINS, José de Souza, 2009, Fronteira: A Degradação do Outro nos Confins do Humano. São Paulo, Hucitec.

MAUSS, Marcel, 2005, Sobre o Sacrifício. São Paulo, Cosac Naify.

MAUSS, Marcel, e Henri HUBERT, 2003, "Esboço de uma teoria geral da magia”, em Marcel Mauss, Sociologia e Antropologia. São Paulo, Cosac Naify, 47-181.

MENEZES, Renata de Castro, 2004, A Dinâmica do Sagrado: Rituais, Sociabilidade e Santidade Num Convento do Rio de Janeiro. Rio de Janeiro, Relume Dumará.

MURPHY, Roseanne, 2008, Mártir da Amazônia: Vida da Ir. Dorothy Stang. São Paulo, Paulus. NORA, Pierre (org.), 1984, Les lieux de mémoire - I: La République. Paris, Gallimard.

NORA, Pierre, 1993, "Entre memória e história: a problemática dos lugares", Projeto História, 10: 7-28.

NOVAES, Sylvia Caiuby, 2006, "Funerais entre os bororo: imagens da refiguração do mundo", Revista de Antropologia, 49 (1): 283-315.

PEIRANO, Mariza (org.), 2002, O Dito e o Feito: Ensaios de Antropologia dos Rituais. Rio de Janeiro, Relume Dumará. 
PEIRANO, Mariza, 2003, Rituais de Ontem e Hoje. Rio de Janeiro, Jorge Zahar.

PEREIRA, Airton dos Reis, 2004, O Papel dos Mediadores nos Conflitos pela Posse da Terra na Região Araguaia Paraense: O Caso da Fazenda Bela Vista, Viçosa, MG, Universidade Federal de Viçosa, dissertação de mestrado em Extensão Rural.

PEREIRA, Airton dos Reis, 2013, A Luta pela Terra no Sul e Sudeste do Pará: Migrações, Conflitos e Violência no Campo, Recife, Universidade Federal de Pernambuco, tese de doutorado em História.

PÉREZ, Andrea Lissett, 2012, “'O exército dos mortos': sentido do sacrifício e da transcendentalidade na militância revolucionária, caso do Exército de Libertação Nacional (ELN) da Colômbia”, Mana, 18 (2): 349-377.

ROSA, Marcelo, 2012, "A terra e seus vários sentidos: por uma sociologia e etnologia dos moradores de fazenda na África do Sul contemporânea", Sociedade e Estado, 27 (2): 361 -385 .

SAHLINS, Marshall, 2008, Metáforas Históricas e Realidades Míticas. Rio de Janeiro, Jorge Zahar.

SAHLINS, Marshall, 2011 , Ilhas de História. Rio de Janeiro, Jorge Zahar.

SILVA, Osnera Pinto da, 2012, Caminhando pelos Mortos, Caminhando pela Vida: Conflitos, Romarias e Santidade no Sudeste Paraense (c. 1980 - c. 2010), Vassouras, RJ, Universidade Severino Sombra, dissertação de mestrado em História.

SOUZA, Edimilson Rodrigues de, 2013, A Morte sob Outro Ponto de Vista: Transformação do Líder Morto em Mártir-Encantado. Vitória, ES, Universidade Federal do Espírito Santo, dissertação de mestrado em Ciências Sociais.

STEIL, Carlos Alberto, 1996, O Sertão das Romarias: Um Estudo Antropológico sobre o Santuário de Bom Jesus da Lapa - Bahia. Petrópolis, Vozes.

TURNER, Victor, 2008, Dramas, Campos e Metáforas: Ação Simbólica na Sociedade Humana. Niterói, EdUFF.

TURNER, Victor, 2013, O Processo Ritual: Estrutura e Antiestrutura. Petrópolis, Vozes.

TURNER, Victor, e Edith TURNER, 2011 , Image and Pilgrimage in Christian Culture. Nova Iorque, Columbia University Press.

VElHO, Otávio Guilherme, 1976, Capitalismo Autoritário e Campesinato. São Paulo, Difel. VELHO, Otávio Guilherme, 1982, Sociedade e Agricultura. Rio de Janeiro, Jorge Zahar. 